\title{
9
}

José Vicente Pérez López*

\section{LA ECONOMÍA DE INDIA EN LA ERA MODI: GRANDES AVANCES Y RETOS}

Desde la victoria de Modi, en las elecciones generales de mayo de 2014, India ha mostrado un sólido crecimiento económico apoyado en unas políticas macroeconómicas prudentes, reformas estructurales y atracción de inversión extranjera directa bajo el programa Make in India. Sin embargo, el crecimiento del PIB comenzó a desacelerarse en la segunda mitad del año 2019 y la crisis de la COVID-19 ha sumido a la economía india en una grave recesión. Los avances en estos últimos años han sido sustanciales y se han reflejado en la mejora de India en la clasificación del Ease of Doing Business y en la atracción de inversión extranjera directa. Sin embargo, existen todavía retos pendientes, cuya acometida será crucial para salir de la actual crisis con celeridad y para cimentar las bases del crecimiento futuro de India.

Palabras clave: India, Modi, crecimiento económico, inversión extranjera directa, Ease of Doing Business.

Clasificación JEL: E66, F21, O53.

\section{Introducción}

Narendra Modi, miembro del Baratiya Janata Party (BJP), un partido tradicional hindú defensor de la libre empresa pero proteccionista frente al exterior, ostenta el cargo de primer ministro desde mayo de 2014. Antes de llegar al primer plano de la política nacional, fue primer ministro del estado de Guyarat desde 2001 hasta 2014. Y fue precisamente en ese cargo donde se granjeó la fama de buen gestor económico, pues supo combinar un robusto crecimiento económico con unas reformas que mejoraron el clima de negocios en el estado. En

Consejero Económico y Comercial en Nueva Delhi. Versión de septiembre de 2020.

DOI: https:/doi.org/10.32796/bice.2020.3128.7889 mayo de 2019 revalidó su victoria en las elecciones generales con una clara mayoría absoluta, lo que supuso un espaldarazo a su política económica.

India ha mostrado en los últimos años un sólido crecimiento económico apoyado en unas políticas macroeconómicas prudentes, reformas estructurales y atracción de inversión extranjera directa (IED) bajo el programa Make in India. El fuerte crecimiento económico de la última década, que se situaba en el entorno del $7,5 \%$ del producto interior bruto (PIB), se desaceleró en 2019 con un crecimiento del 4,2\%, en línea con una caída del crecimiento mundial. La crisis de la COVID-19 está afectando a India mucho más de lo previsto inicialmente. EI Fondo Monetario Internacional (FMI) ha ido $\triangleright$ 
recortando sucesivamente sus previsiones de crecimiento para el actual año fiscal 2020-2021 hasta dejarlo en una previsión de recesión del $-4,5 \%$. Sin embargo, aunque los últimos datos de actividad del mes de agosto de 2020 apuntan a que lo peor de la crisis podría haber pasado ya, la incertidumbre existente sobre la evolución de la pandemia lastra el crecimiento y no es posible descartar aún mayores ajustes a la baja en el mismo.

En el contexto actual, la crisis sanitaria de la COVID-19 y su consecuente crisis económica son la principal preocupación del Gobierno indio. Por tanto, la gestión de salida de la crisis, con el menor coste humano posible, es prioritaria. En este sentido, las medidas adoptadas por el Gobierno son adecuadas, aunque el impulso fiscal podría haber sido mayor. Sin embargo, la nueva política Self-Reliant India podría suponer un freno al crecimiento en el medio plazo. Así, se han prohibido determinadas importaciones, se han limitado las licitaciones globales, se quiere pasar a un régimen de licencias en determinados sectores e India parece alejarse de posiciones favorables al libre comercio para consolidar su tendencia de proteccionismo nacionalista. Por ello, en el largo plazo, debería mantenerse el ímpetu reformista que aumente el crecimiento potencial del país.

\section{Evolución macroeconómica}

El crecimiento de la economía india se ha sido situado cercano al $7 \%$ durante todo el mandato de Narendra Modi, a excepción del año fiscal 2019-20201', que ha cerrado en el $4,2 \%$. Aunque India ya venía creciendo a ritmos del $7 \%$ durante los diez años previos al inicio del mandato de Modi, ha sabido combinar en los últimos seis años un sólido crecimiento con unas políticas económicas prudentes y unas reformas estructurales que han mejorado sustancialmente la economía de mercado del país.

Este crecimiento económico ha sido superior al incremento medio de los países emergentes, que se ha situado, según el Fondo Monetario Internacional, en el 4,6\% durante los años 2014-2018, y ligeramente superior al de los países emergentes de Asia, que han registrado un crecimiento medio del $6,7 \%$ durante el mismo periodo.

En mayo de 2019, Modi recibe por segunda vez un amplio apoyo en las elecciones generales, que gana con una clara mayoría absoluta. Esta victoria supone un refrendo de su política económica y una confianza para continuar el camino marcado en su primer mandato. El objetivo principal de este segundo mandato a nivel económico es conseguir que la economía india alcance los cinco billones de dólares. Sin embargo, la leve desaceleración del crecimiento que comenzó en el año 2018-2019 se ha acentuado en el año 2019-2020, especialmente por el impacto de la COVID-19. Esta $\triangleright$

1 En India los años fiscales abarcan el periodo que va desde el 1 de abril hasta el 31 de marzo del año siguiente.

TABLA 1

CRECIMIENTO DE INDIA

(En porcentaje del PIB)

\begin{tabular}{|c|c|c|c|c|c|}
\hline $\begin{array}{c}\text { Periodo 2003-2004 } \\
\text { a 2007-2008 }\end{array}$ & $\begin{array}{c}\text { Periodo 2009-2010 } \\
\text { a 2013-2014 }\end{array}$ & $\begin{array}{c}\text { Media 2013-2014 } \\
\text { a 2019-2020 }\end{array}$ & $\mathbf{2 0 1 7 - 2 0 1 8}$ & $\mathbf{2 0 1 8 - 2 0 1 9}$ & $\mathbf{2 0 1 9 - 2 0 2 0}$ \\
\hline 7,9 & 6,7 & 6,8 & 7 & 6,1 & 4,2 \\
\hline
\end{tabular}


TABLA 2

INFLACIÓN GENERAL EN INDIA MEDIDA POR EL WHOLESALE PRICE INDEX E IPC

\begin{tabular}{|c|c|c|c|c|c|c|c|}
\hline & $\mathbf{2 0 1 3 - 2 0 1 4}$ & $\mathbf{2 0 1 4 - 2 0 1 5}$ & $\mathbf{2 0 1 5 - 2 0 1 6}$ & $\mathbf{2 0 1 6 - 2 0 1 7}$ & $\mathbf{2 0 1 7 - 2 0 1 8}$ & $\mathbf{2 0 1 8 - 2 0 1 9}$ & $\mathbf{2 0 1 9 - 2 0 2 0}$ \\
\hline WPI & 5,2 & 1,2 & $-3,7$ & 1,7 & 3 & 4,3 \\
\hline IPC & 9,4 & 5,9 & 4,9 & 4,5 & 3,6 & 3,4 \\
\hline
\end{tabular}

desaceleración obedece a factores externos y domésticos. Por un lado, la desaceleración del crecimiento global (resurgimiento de tensiones comerciales, Brexit, ralentización de China) es importante. Este pasó del 3,6\% en 2018 al 2,9\% en 2019 y provocó una caída de la demanda externa y de las exportaciones indias. Sin embargo, la ralentización en India ha sido mayor. Así, mientras que en el año 2019, de acuerdo al FMI, la economía de los países emergentes se ralentizó de media 0,8 puntos porcentuales, en China esta desaceleración fue de 0,6 puntos porcentuales y en India de 1,9 puntos porcentuales. Desde un punto de vista interno, los factores domésticos detrás de este peor comportamiento de India serían las fuertes caídas de los sectores de automoción e inmobiliario y la de la demanda rural, las tensiones en el sector financiero no bancario y la caída de la inversión.

Las políticas aplicadas para hacer frente a esta ralentización han sido anticíclicas y expansivas. Por un lado, la política monetaria ha sido acomodaticia y el tipo de interés de referencia se ha reducido en 250 puntos básicos desde febrero de 2019 y las inyecciones de liquidez se han situado cerca del $5 \%$ del PIB. Además, esta política monetaria acomodaticia ha sido compatible con una inflación controlada y dentro de los límites fijados por el propio banco central (Reserve Bank of India, o RBI, por sus siglas en inglés), que fijan un objetivo de inflación del $4 \%$ con unas bandas de variación de más menos 2 puntos porcentuales. Así, a pesar de un pequeño repunte de la inflación por encima del $6 \%$ a final del año 2019 , la inflación media del periodo 2019-2020 se ha quedado en el $4,8 \%$.

La inflación se ha mantenido bajo control y con una tendencia a la baja desde el año 2014. Aunque esta moderación ha sido común en la mayoría de los países emergentes, es cierto que la reducción de la inflación de alimentos, la adopción de reformas estructurales y la implantación de un objetivo claro de inflación, desde el año 2016, han jugado un papel fundamental. Así, desde el año 2016, la inflación media se ha situado en el 3,9\%, muy alineada con el objetivo del $4 \%$. Esto ha favorecido la confianza de los inversores y ha anclado las expectativas de inflación. Además, ha permitido que la política monetaria se oriente al crecimiento cuando se ha requerido estimular la economía y dotar de liquidez al sistema financiero para que este continúe funcionando con normalidad durante la pandemia.

Desde un punto de vista fiscal, el margen disponible ha sido menor, y eso ha condicionado el grado de expansión de la política fiscal aplicado. Sin embargo, dentro de ese margen disponible, el objetivo ha sido claro: consolidar fiscalmente las cuentas públicas y apoyar el crecimiento cuando ha sido necesario. Así, en los primeros años del mandato de Modi, con elevados crecimientos del PIB, el déficit público se redujo paulatinamente, y cuando la ralentización empezó a agravarse en la segunda mitad del año 2019, el Gobierno indio no tardó $\triangleright$ 
en reaccionar y aprobó un paquete de estímulo fiscal centrado en un fuerte recorte del impuesto de sociedades, del $30 \%$ al $22 \%$, que a su vez buscaba equiparar el régimen impositivo indio al de otros países del sudeste asiático para incrementar la atracción de IED. Este carácter expansivo y contracíclico de la política fiscal frenó la reducción del déficit. A pesar de ello, los objetivos fiscales de medio plazo siguen siendo alcanzar un déficit del $3 \%$ a cierre de año fiscal 2020-2021 y una deuda pública del Gobierno central del $44,4 \%$ del PIB. Sin embargo, estos objetivos fiscales se fijaron en julio de 2019 , cuando todavía la ralentización de final de año no se había producido y la COVID-19 era desconocida. Por tanto, desviaciones fiscales de estos objetivos son más que previsibles en la actualidad. De hecho, el año fiscal 2019-2020, que preveía cerrar con un déficit del 3,3\%, ha terminado el año en el 4,6\%. Este desvío fiscal se ha debido a la caída de la recaudación a consecuencia de la desaceleración económica y del nuevo tipo inferior del impuesto de sociedades.

\section{Reformas estructurales adoptadas}

India ha llevado a cabo variadas e importantes reformas estructurales durante los últimos seis años, de las cuales destacaría la creación de un impuesto sobre el valor añadido a nivel nacional (Goods and Services Tax, o GST, por sus siglas en inglés).

Todas estas reformas se enmarcan en el programa nacional del Gobierno denominado Make in India, cuyo lanzamiento tuvo lugar en el día de la Independencia (15 de agosto) del primer año del mandato de Modi. Este programa busca convertir a India en el mayor hub manufacturero mundial. Para ello es indispensable atraer IED y, por ese motivo, busca facilitar las inversiones, fomentar la innovación, mejorar la formación y proteger la propiedad intelectual. Además, mejorar el clima de negocios en el país es fundamental, y esa es la razón por la que, con el fin de mejorar en el ranking del Banco Mundial, Ease of Doing Business, ha sido prioritario año tras año. El cumplimiento de este objetivo tendría un claro impacto en el empleo y en el crecimiento económico.

Este programa se centra en 25 sectores clave: automoción, aviación, químico, información tecnológica, farmacéutico, construcción, defensa, maquinaria eléctrica, procesado de alimentos, textil, puertos, cuero, medios de comunicación y entretenimiento, bienestar, minería, gas y petróleo, turismo y restauración, ferrocarril, componentes de automoción, energía renovable, biotecnología, aeroespacial, energía térmica, carreteras y sistemas electrónicos.

Para favorecer el Make in India, existen distintos programas de incentivos a nivel central o estatal ${ }^{2}$, y además se han llevado a cabo, entre otras, las siguientes reformas estructurales:

\section{Goods and Services Tax}

La introducción del GST fue la reforma estrella del primer mandato de Modi. EI GST $\square$

2 Estos programas pueden consultarse en www. makeinindia.com

TABLA 3

DÉFICIT DEL GOBIERNO CENTRAL

(En porcentaje del PIB)

\begin{tabular}{|c|c|c|c|c|c|c|}
\hline Año & $\mathbf{2 0 1 4 - 2 0 1 5}$ & $\mathbf{2 0 1 5 - 2 0 1 6}$ & $\mathbf{2 0 1 6 - 2 0 1 7}$ & $\mathbf{2 0 1 7 - 2 0 1 8}$ & $\mathbf{2 0 1 8 - 2 0 1 9}$ & $\mathbf{2 0 1 9 - 2 0 2 0}$ \\
\hline Déficit público & 4,1 & 3,9 & 3,5 & 3,5 & 3,4 & 4,6 \\
\hline
\end{tabular}


se introdujo el 1 de julio de 2017 y reemplazó ocho impuestos centrales y nueve impuestos estatales, aunque dejó al petróleo y al alcohol fuera de su ámbito. De esta manera se simplificó sustancialmente el sistema impositivo con el objetivo de mejorar el clima de negocios y aumentar la capacidad recaudatoria. Las principales beneficiarias de este nuevo impuesto han sido las pequeñas y medianas empresas, que en India son la espina dorsal de la economía. Al ser el nuevo sistema más simple y al eliminarse las disparidades estatales, las pymes han visto disminuir su esfuerzo dedicado a esta labor. Además, se ha fijado un umbral que exime a las empresas más pequeñas de presentar GST.

\section{El Código de Insolvencia y Bancarrota}

La reforma de la resolución de empresas necesitaba ser acometida en India. Según el Banco Mundial, en 2016, en países como Japón la duración media de los procesos de resolución era de 0,6 años; en Canadá, de 0,8; en Estados Unidos, de 1,5; y en China, de 1,7 años. Sin embargo, en India estos procesos tenían una duración media de 4,3 años. Por tanto, la reforma de los procedimientos concursales para acelerarlos, maximizar los activos en concurso y asegurar un equilibrio entre todas las partes implicadas era clave y necesaria para sanear al mismo tiempo el sistema financiero. Así, en mayo de 2016, el Parlamento indio aprobó la ley que daba forma a este código.

\section{Desmonetización}

Aunque quizás no sea esta una de las medidas más efectivas de su primer mandato, sí será una de las más recordadas por el fuerte impacto que causó entre los ciudadanos. El
8 de noviembre de 2016 Modi anunció que los billetes de 500 y 1.000 rupias dejarían de tener validez esa misma medianoche, lo que suponía el $86 \%$ del efectivo en circulación. El objetivo era terminar con el dinero negro o falsificado y asestar un duro golpe a las actividades delictivas. Además, pretendía conseguir una mayor digitalización de la economía. Sin embargo, estudios posteriores aseguran que prácticamente el cien por cien de estos billetes fueron devueltos a los bancos y que, por tanto, esta medida no fue muy efectiva. De hecho, afectó duramente a sectores muy dependientes del dinero en efectivo y a la pequeña economía informal. No obstante, sirvió para introducir en el circuito bancario dinero que estaba al margen hasta el momento, lanzar un mensaje importante sobre la lucha contra la corrupción y consolidar la imagen de fuerza del primer ministro.

\section{Pradhan Mantri Jan Dhan Yojana}

Este programa para promover la inclusión financiera fue anunciado por Modi durante su primer discurso del día de la Independencia en 2014. Este programa ha permitido que más de 400 millones de personas ${ }^{3}$ tengan acceso a una cuenta corriente, tarjetas de débito y acceso a programas de la seguridad social. El $60 \%$ de los beneficiarios se encuentran en zonas rurales y el saldo total que se ha bancarizado asciende a 1.130 .000 millones de rupias.

\section{La reforma de la Ley de Arbitraje y Conciliación}

La reforma de la Ley de Arbitraje ha acelerado la resolución de disputas comerciales puesto que ahora todas deben finalizar en un $\triangleright$

\footnotetext{
3 https://pmjdy.gov.in
} 
máximo de doce meses. Además, ha resuelto conflictos de interés de los árbitros y ha aumentado la transparencia. Esta reforma llevada a cabo en agosto de 2019 era muy necesaria, pues la resolución de las disputas comerciales en India es muy costosa cuando se acude a los tribunales.

\section{Mejora en el Ease of Doing Business y en atracción de IED}

Todas las reformas estructurales llevadas a cabo han mejorado sustancialmente la posición de India en el ranking del Banco Mundial del Ease of Doing Business y han favorecido la atracción de IED.

En la Tabla 4 se puede observar cómo en el año 2014 India ocupaba la posición 142 en la clasificación del Banco Mundial del Ease of Doing Business y en el año 2019 ha ascendido hasta la posición 63. Las mejoras han sido sustanciales en seis de los diez parámetros medidos en el ranking. De todas las reformas comentadas con anterioridad destacan el GST y el nuevo Código de Insolvencia y Bancarrota, que han sido las que han propiciado la fuerte subida en el ranking actual. Sin embargo, en cuestión de apertura de una empresa (puesto 136), registro de propiedades (154), pago de impuestos (puesto 115) y cumplimiento de contratos (163), India continúa en posiciones muy retrasadas.

$Y$ es que, si comparamos India con otros países emergentes, apreciamos que el margen de mejora es todavía amplio. Así, China, Rusia y Turquía ostentan las posiciones 31, 28 y 33, respectivamente, en la clasificación. Lógicamente, esas posiciones superiores suponen que las diferencias en las distintas variables sean sustanciales y siempre favorables a estos países. Pero es que estas diferencias se acrecientan cuando nos referimos a las variables donde el comportamiento relativo de India es más débil.

Es cierto que India ha superado en el ranking a otros países comparables, como podrían ser Sudáfrica (posición 84), Indonesia (posición 73) o Brasil (posición 124). Sin embargo, en cuestión de apertura de una empresa, registro de propiedades, pago de impuestos y cumplimiento de contratos, el comportamiento de India es similar o incluso peor que el de estos otros países.

TABLA 4

INDIA EN LA CLASIFICACIÓN DEL EASE OF DOING BUSINESS

\begin{tabular}{|l|r|r|r|r|r|r|r|r|}
\hline \multicolumn{1}{|c|}{ Año } & $\mathbf{2 0 1 2}$ & $\mathbf{2 0 1 3}$ & $\mathbf{2 0 1 4}$ & $\mathbf{2 0 1 5}$ & $\mathbf{2 0 1 6}$ & $\mathbf{2 0 1 7}$ & $\mathbf{2 0 1 8}$ & $\mathbf{2 0 1 9}$ \\
\hline POSICIÓN GLOBAL & $\mathbf{1 3 2}$ & $\mathbf{1 3 4}$ & $\mathbf{1 4 2}$ & $\mathbf{1 3 0}$ & $\mathbf{1 3 0}$ & $\mathbf{1 0 0}$ & $\mathbf{7 7}$ & $\mathbf{6 3}$ \\
Apertura de una empresa & 173 & 179 & 158 & 155 & 155 & 156 & 137 & 136 \\
Manejo de permisos de construcción & 182 & 182 & 184 & 183 & 185 & 181 & 52 & 27 \\
Obtención de electricidad & 105 & 111 & 137 & 70 & 26 & 29 & 24 & 22 \\
Registro de propiedades & 94 & 92 & 121 & 138 & 138 & 154 & 166 & 154 \\
Obtención de crédito & 23 & 28 & 36 & 42 & 44 & 29 & 22 & 25 \\
Protección de inversores minoritarios & 49 & 34 & 7 & 8 & 13 & 4 & 7 & 13 \\
Pago de impuestos & 152 & 158 & 156 & 157 & 172 & 119 & 121 & 115 \\
Comercio transfronterizo & 127 & 132 & 126 & 133 & 143 & 146 & 80 & 68 \\
Cumplimiento de contratos & 184 & 186 & 186 & 178 & 172 & 164 & 163 & 163 \\
Resolución de la insolvencia & 116 & 121 & 137 & 136 & 136 & 103 & 108 & 52 \\
\hline Fuente: elaboración propia a partir del informe Ease of Doing Business & $\mathbf{2 0 2 0 .}$ & & & &
\end{tabular}


- La apertura de un negocio implica diez procedimientos que se alargan 17-18 días en India. En cambio, en Indonesia o Brasil, aunque se requieren once procedimientos para abrir una empresa, en Indonesia se tardan cuatro días menos que en India, y en Brasil se tarda el mismo tiempo. Además, países como Sri Lanka o Pakistán puntúan mejor en este parámetro que India.

- El registro de una propiedad tarda 58 días y supone un coste medio del $7,8 \%$ del valor de la misma en India. En China, sin embargo, el registro de la propiedad se realiza en tan solo nueve días y el coste del registro es del 4,6\% del valor de la propiedad. En Brasil o Indonesia, por ejemplo, el registro de la propiedad tarda 31 días y el coste supone el 3,6\% y el $8,3 \%$, respectivamente. Además, en todos los países, excepto en Brasil, el número de procedimientos para registrar una propiedad es menor.

- En cumplimiento de contratos (posición 163), es difícil encontrar países cuyo desempeño sea peor que el de India. Así, en India se tarda cuatro años de media en solventar una disputa comercial a través de un tribunal de justicia de primera instancia, mientras que en Indonesia, China o Brasil se tarda 1,2, 1,4 y 2,2 años, respectivamente.

- En pago de impuestos, India ha mejorado mucho. Ha reducido el número de pagos por año de 59 a 12 en los últimos años, pero el tiempo dedicado a esta actividad no se ha reducido en la misma medida. En India se dedican 250 horas anuales al pago de impuestos. En cambio, en China, el número de pagos anuales es de 7 y el tiempo dedicado a esta labor es de 138 horas anuales. La comparación con Brasil e Indonesia es mixta. Por un lado, Brasil tiene menores pagos al año que India, pero dedica más tiempo a esta actividad. Por otro lado, es llamativo que Indonesia tenga 26 pagos de impuestos al año pero que el tiempo invertido en presentar todos esos pagos sea significativamente menor que en India (191 horas).

En el caso de la restauración, la comparación también es sorprendente y muy ilustrativa. Según la Asociación Nacional de Restaurantes de India, se requieren 36 certificados para abrir un restaurante en Bangalore, 26 en Delhi y 22 en Mumbai. Además, en Delhi o Calcuta se necesita una licencia de la Policía para abrir el restaurante. Esta licencia de la Policía requiere presentar 45 documentos en Delhi, que es significativamente mayor que el número de documentos requeridos para obtener una licencia de armas (19). En China, sin embargo, solo se requieren cuatro licencias para abrir un restaurante.

El espejo lógico en el que se debería mirar India es China, sobre todo teniendo en cuenta los esfuerzos que está realizando el Gobierno indio para captar la eventual IED saliente de China a raíz de la crisis de la COVID-19. En primer lugar, porque el cambio de las cadenas de suministro globales es costoso y conlleva tiempo. Pero es que, en segundo lugar, muchos beneficios tendría que aportar la deslocalización de China para que una multinacional decida implantarse en un país donde la operativa de hacer negocios sea más complicada y costosa. Como se suele decir: para ese viaje no hacían falta alforjas.

En este contexto, la cuestión de la ineficiencia logística es también reseñable, pues la competitividad de las exportaciones no solo $\square$ 
depende del coste de producción, sino también del coste logístico. En unos casos de estudio realizados con ocasión de la Economic Survey 2019-2020 del Ministerio de Finanzas indio, se ha analizado cuánto tarda una mercancía en desplazarse por las distintas fases de la cadena de suministro global. Así, se ha visto cómo se tarda entre siete y diez días de media en que una mercancía llegue a puerto en India, mientras que en países como China, Bangladés o Vietnam se tarda solo un día. Además, la gestión de la mercancía y el despacho de aduana en los puertos indios es altamente ineficiente, y existen retrasos con mucha variabilidad. Esta gestión y carga de la mercancía supone días de espera cuando en otros países se hace en cuestión de horas. Por ejemplo, uno de los casos de estudio ha mostrado cómo un envío de textiles desde Delhi (India) hasta Maine (Estados Unidos) tarda 41 días, de los cuales 19 transcurren por territorio indio debido a retrasos e ineficiencias en todas las etapas del proceso de exportación. Otro de los casos de estudio refleja resultados similares para la exportación de unas alfombras desde Uttar Pradesh (India) hasta Estados Unidos.

Esta ineficiencia en los puertos se ha puesto de manifiesto durante los meses de confinamiento a causa de la pandemia. En teoría, el tráfico internacional de mercancías debería haber funcionado con normalidad. Sin embargo, a las ineficiencias comunes existentes se les han sumado otros retrasos ocasionados por el confinamiento (personal de aduana en mínimos, falta de personal en los puertos por imposibilidad de trasladarse a sus puestos de trabajo debido a la falta de transporte público, etc.). Por estas razones, en la práctica, la mercancía se ha ido acumulando en los puertos y en algunos, donde se ha llegado al colapso, la mercancía ha tenido que acumularse en barcos contenedores fuera de los puertos. La consecuencia final ha sido un impacto mayor en las exportaciones e importaciones indias durante los meses de marzo, abril y mayo, y una mayor disrupción en las cadenas de suministros indias e internacionales. Esta cuestión no es baladí. Durante los meses más duros de la pandemia en Europa, y en el caso del suministro de formulaciones o principios activos de medicamentos, donde India es uno de los principales proveedores mundiales, el elevado retraso en los envíos ha mermado la credibilidad y la confianza en India y ha forzado a clientes europeos a buscar alternativas más fiables.

Otro buen indicador del éxito de la evolución macroeconómica y de las reformas estructurales adoptadas es el flujo de entrada de IED en India ${ }^{4}$. La tendencia experimentada ha sido muy positiva desde el año 2014 y muestra la confianza de los inversores internacionales por esta economía en el largo plazo. Así, la IED recibida por India desde abril de 2014 hasta marzo de 2020 (357.350 millones de USD) supone el $52,5 \%$ del total de IED recibida por el país desde abril del año 2000 (680.910 millones de USD). Además, India ha cruzado por primera vez el umbral de los 70.000 millones de USD recibidos en el año fiscal 2019-2020. Por último, cabe subrayar que, si con anterioridad a 2014 se alternaban años con crecimientos con años de caídas en la IED recibida, desde 2014 la IED ha experimentado siempre crecimientos anuales positivos.

El sector servicios ha sido el mayor receptor de esta inversión, con un $17 \%$ del total en el periodo abril 2000-marzo 2020. En el último año 2019-2020 también ha sido el mayor receptor, con 7.850 millones de USD. Por su parte, el $\triangleright$

4 https://dipp.gov.in/sites/default/files/FDI_Factsheet_ March20_28May_2020.pdf 


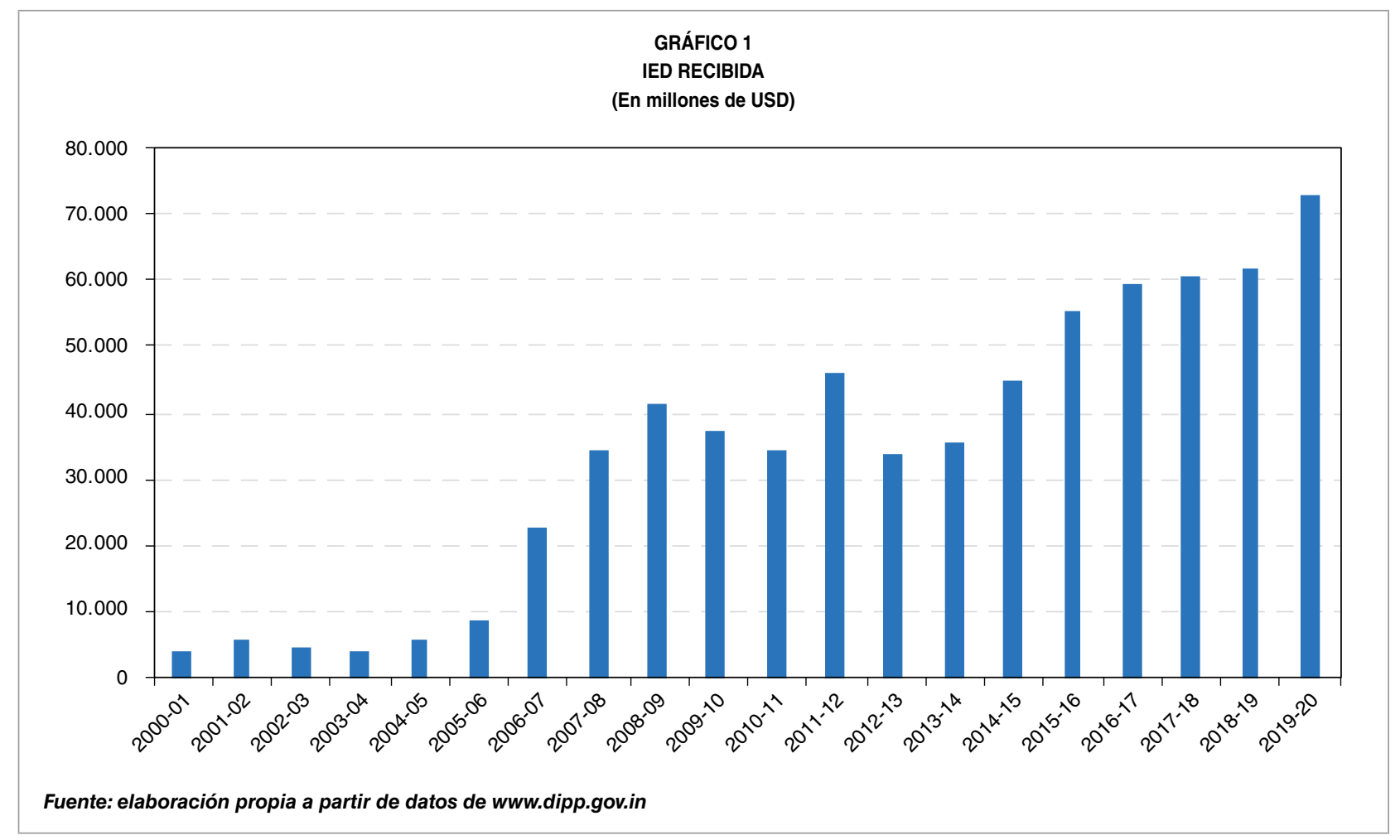

sector de automoción y sus componentes es el que está creciendo a mayor ritmo, pues en los últimos dos años ha aumentado su inversión un $35 \%$. Otro sector cuya inversión ha crecido con fuerza es el de telecomunicaciones, que supone el $8 \%$ del total recibida en los últimos veinte años y en el último año casi duplica a la del año anterior.

Por estados, Maharashtra, Karnataka, Delhi y Gujarat, con un $30 \%, 18 \%, 17 \%$ y $11 \%$ del total, respectivamente, han sido los que mayor cifra de inversión han recibido en el periodo octubre 2019-marzo 2020.

Por último, si atendemos a los países de origen de estas inversiones, destacan por motivos fiscales Mauricio y Singapur, que ostentan entre los dos el $51 \%$ del total de los flujos de inversión con destino India. Por detrás podemos encontrar a Países Bajos (7\%), Japón (7\%), Estados Unidos (6\%), Reino Unido (6\%) y Alemania (3\%). China, que ha estado bajo el foco mediático durante la pandemia y cuyas inversiones en India quedaron sujetas a aprobación gubernamental durante este verano, se encuentran en la 18. ${ }^{\text {a }}$ posición, con tan solo un $0,5 \%$ del total de inversión acumulada durante el periodo abril 2000-marzo 2020.

Esta positiva evolución de la IED es más destacable aún si la comparamos con la tendencia global de reducción de flujos de IED. EI último informe de la Conferencia de Naciones Unidas sobre Comercio y Desarrollo (UNCTAD), titulado World Investment Report 2020, subraya que las cifras de IED recibidas a nivel global se han reducido desde 2015. Así, a pesar del leve crecimiento del $3 \%$ en el año 2019 , los flujos de IED entrante cayeron un $14 \%$ y un $12 \%$ en 2017 y 2018, respectivamente. Además, a causa de la pandemia, se espera que estos flujos se contraigan a nivel global entre un 30 y un $40 \%$ en el año 2020. Por último, el comportamiento de estos flujos en Asia, que representan aproximadamente un tercio del total, cayeron un $1 \%$ y un $5 \%$ en los últimos dos años, y $\triangleright$ 


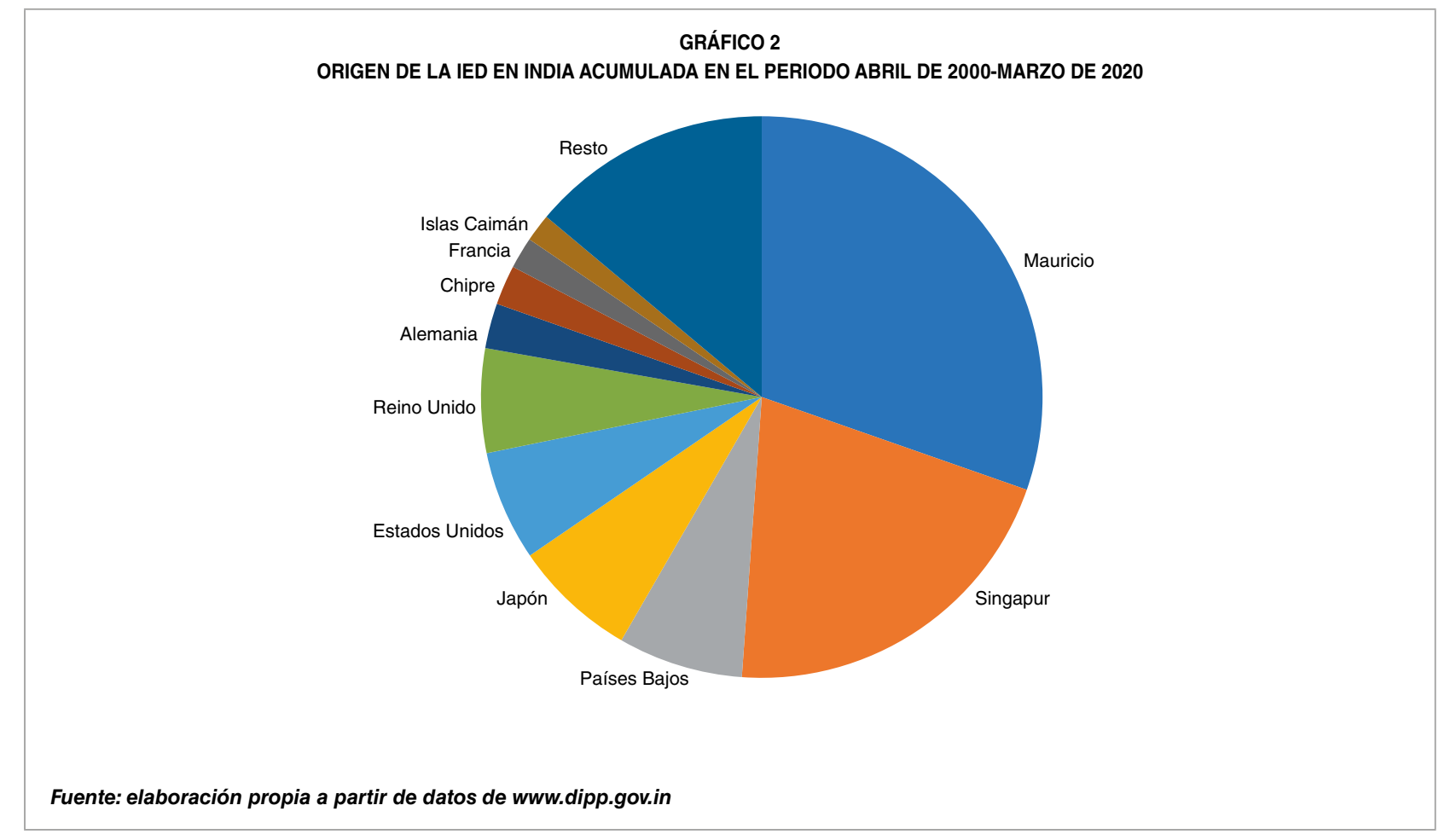

se espera una caída del $30-45 \%$ en el año 2021. Con esta perspectiva y en un contexto de desaceleración de su PIB, los flujos de IED recibida por India son un claro indicador del potencial del país. El informe de la UNCTAD señala que India continuará atrayendo inversión a pesar de la pandemia por su gran tamaño de mercado. Además, el sector de los servicios profesionales y de la economía digital, que son los que suscitan mayor interés, seguirán liderando las cifras en el futuro cuando grandes compañías a nivel mundial acudan al mercado indio para crecer vía fusiones y adquisiciones. En el sector de la energía también podrán producirse operaciones, como la reciente adquisición del $50 \%$ de los proyectos solares de Adani Energy por la francesa Total, valorada en 800 millones de USD. Asimismo, el informe menciona que el crecimiento de la inversión en el sudeste asiático se debe a India, que ha continuado relajando las barreras a la inversión. Así, por ejemplo, a mediados de 2019 relajó los requisitos de inversión en los sectores de comercio minorista, seguros y carbón. En 2019 se produjeron grandes acuerdos de fusión en el sector de compañías de internet por valor de 2.700 millones de USD y la adquisición de Essar Steel (India) por una joint venture japonesa-india. Estos acuerdos se suman a la sonada adquisición del $77 \%$ de Flipkart por Walmart en mayo de 2018 por un valor de 16.000 millones de USD o a la entrada en India de grandes marcas en 2017 como Huawei, Zopo Mobile, Panasonic o Havells, entre otras.

\section{Impacto y reacción a la COVID-19}

India ha reaccionado de manera temprana a la COVID-19, pero el impacto será significativo a nivel sanitario y económico. El 25 de marzo de 2020 el Gobierno confinó de manera muy estricta a más de 1.350 millones de personas, cuando el número de casos en el país $\square$ 
no llegaba a los 500. Este confinamiento duró dos meses y posteriormente ha ido flexibilizándose paulatinamente. Esta reacción temprana ha servido para ganar tiempo y ayudar en la preparación sanitaria de la pandemia. Sin embargo, ha servido para retrasar, pero no para detener la pandemia, pues a día de hoy India es el segundo país del mundo con mayor número de casos de contagios, por detrás de Estados Unidos, y al ritmo actual todo parece indicar que será el país más afectado por la pandemia antes de final de año. Además, el estricto confinamiento ha tenido un impacto económico enorme por el cierre de actividad. $A$ este hecho se une que aquellas actividades que, en teoría, eran esenciales y deberían haber seguido funcionando con normalidad tampoco pudieron funcionar correctamente debido a graves problemas logísticos y de la cadena de suministros.

Así las cosas, India ha entrado en recesión rápidamente, y ahora el $\mathrm{FMl}$ espera, según la actualización del World Economic Outlook (WEO) de junio de 2020, que la economía india se contraiga un $-4,5 \%$ en el año fiscal 2020-2021. Si bien es cierto que esta recesión es común a todos los países del mundo, también lo es que la revisión a la baja del crecimiento indio respecto a la previsión de abril 2020 es la mayor (-6,5 puntos porcentuales) entre todos los países emergentes que aparecen relacionados en el WEO de junio de 2020. La Organización para la Cooperación y el Desarrollo Económicos (OCDE), por su parte, estima dos escenarios $(-3,7 \%$ o $-7,3 \%)$ para la recesión india este año en función de la gravedad de la segunda ola de contagios. Dado que en India todavía no se ha llegado al pico de la primera ola, difícilmente podremos alinearnos con el escenario más optimista. Y así lo muestra el último dato de crecimiento de PIB publicado por el Ministerio de Estadística indio, que refleja una contracción del -23,9\% en el primer trimestre del año fiscal 2020-2021 (abril-junio 2020). Esta caída, la más severa entre todos los países del G20, tiene su origen en el confinamiento de 68 días que comenzó el 25 de marzo y que ha impactado fuertemente en la demanda, aumentado el ahorro precautorio y eliminando cualquier tipo de inversión en un contexto de elevada incertidumbre. Sin embargo, no debemos olvidar que la COVID-19 ha agravado el impacto en una economía que ya se venía desacelerando con fuerza, pues en el primer trimestre del año 2020 el PIB creció solamente un $3,1 \%$, cifra que representaba la menor tasa de crecimiento de los últimos ocho años. Así, aunque el dato de agosto del Índice de Gestor de Compras (PMI) manufacturero muestra un crecimiento mensual por primera vez desde abril y esto podría indicar que lo peor de la crisis podría haber pasado ya, la incertidumbre existente sobre la evolución de la pandemia lastra el crecimiento y no es posible descartar aún mayores ajustes a la baja en el mismo.

Las medidas adoptadas para luchar contra esta crisis han sido cuantiosas. Según el FMI, el paquete de estímulo, entre medidas fiscales $y$ de liquidez, se ha situado en media en el $12,1 \%$ para los países del G20 $(5,1 \%$ en el caso de países emergentes y $19,8 \%$ en el caso de economías avanzadas). El Gobierno indio, por su parte, ha reaccionado con un paquete económico de estímulo fiscal y monetario estimado en un $10 \%$ del PIB. Este estímulo ha supuesto un aumento del déficit público previsto para este año del 1,5\% del PIB y un recorte continuado de los tipos de interés de referencia del RBI hasta el $4 \%$ actual. Además, el Gobierno indio ha llevado a cabo medidas comerciales de restricción de exportaciones y de exención de aranceles a la importación de $\triangleright$ 
determinados productos médicos y farmacéuticos para luchar contra la COVID-19. Por último, también ha anunciado reformas estructurales en determinados sectores para relanzar el crecimiento económico.

\subsection{Medidas fiscales}

El 24 de marzo, el mismo día en que se decretó el confinamiento, la ministra de Finanzas india anunció unas medidas impositivas entre las que se incluían prórrogas en la declaración de la renta, en declaración del IVA y otros impuestos, y la reducción de la tasa de interés por pagos atrasados del $12 \%$ al $9 \%$. Con la declaración de confinamiento también se anunció un paquete de emergencia para sanidad próximo a los 2.000 millones de euros y la participación del sistema de salud privado en la lucha contra la crisis sanitaria.

Dos días después, el 26 de marzo, se anunció un paquete de estímulo fiscal que en realidad era un paquete de ayuda de unos 20.000 millones de euros destinados a los segmentos más pobres de la población. Entre otras medidas, este paquete incluía transferencias directas de efectivo y seguridad alimentaria, a través de la entrega de $5 \mathrm{~kg}$ de arroz y $1 \mathrm{~kg}$ de legumbres, durante los siguientes tres meses a las familias más pobres.

El martes 12 de mayo Modi anunció un paquete de medidas económicas por un valor de 250.000 millones de euros, equivalente a un $10 \%$ del PIB. Según el anuncio de Modi, el paquete incluiría reformas laborales y en la adquisición de tierra, así como inyecciones de liquidez adicionales. También se haría un especial hincapié en las pymes y en la atracción de inversión extranjera. Además, afirmó que se estaba barajando dar exenciones fiscales a las nuevas inversiones en determinados sectores (aparatos médicos, electrónica, telecomunicaciones o bienes de equipo). Las inversiones en infraestructura también serían parte del paquete. Por último, lanzó una campaña denominada Self-Reliant India, o India autosuficiente, por la que animaba a producir y consumir localmente.

La primera parte de este paquete de medidas fue anunciada por la ministra de Finanzas el miércoles 13 de mayo. Las principales medidas anunciadas estuvieron centradas en las pymes y fueron las siguientes:

- Préstamos sin garantía para las pymes por un montante equivalente al $1,5 \%$ del PIB.

- Las licitaciones globales (con participación de empresas extranjeras) se eliminarían para los contratos del sector público que fueran inferiores a los 25 millones de euros.

- El Gobierno y las empresas públicas pagarían a las pymes en los próximos 45 días sus cuentas por cobrar.

- Rebaja del 12 al 10\% de las contribuciones al Employee Provident Fund por parte de las organizaciones y de sus empleados durante los siguientes tres meses.

- Inyección de liquidez de 11.250 millones de euros a las empresas de distribución de energía (Discoms) para que puedieran pagar las cuentas pendientes de cobro de sus clientes.

La segunda parte del paquete económico fue anunciada el jueves 14 de mayo y se centró en agricultores, trabajadores migrantes y vendedores callejeros. Se anunciaron facilidades especiales de crédito para los vendedores callejeros, ayuda alimentaria para $\triangleright$ 
trabajadores migrantes y ayuda de crédito para agricultores.

El viernes 15 de mayo la ministra de Finanzas anunció la tercera parte del paquete de medidas, centrado en agricultura y pesca. De este modo, se pretendía satisfacer las demandas de dos sectores considerados la base de la producción doméstica: las pymes y la agricultura. Las medidas anunciadas tienen como objetivo modernizar las infraestructuras agrarias y fomentar la economía de mercado en el sector.

\subsection{Medidas monetarias}

El 27 de marzo, el RBI redujo la tasa de interés de referencia en 75 puntos básicos desde el $5,15 \%$ hasta el $4,4 \%$ con el objetivo de estimular y dar liquidez a la economía por la desaceleración causada por la pandemia mundial.

El 17 de abril, el RBI anunció su segundo paquete de medidas para aumentar la liquidez, en especial a ciertos sectores: compañías financieras no bancarias (NBFC, por sus siglas en inglés), bancos y gobiernos estatales.

El 22 de mayo, el RBI redujo nuevamente la tasa de interés de referencia en 40 puntos básicos hasta el $4 \%$.

El Comité de Política Monetaria del RBI espera que el crecimiento del año 2020-2021 sea negativo, tanto más cuanto más se prolongue la pandemia. Ante esta situación, considera que hay margen para continuar bajando tipos, pero tiene que utilizar los instrumentos a su alcance con inteligencia y en el momento oportuno para garantizar que sus beneficios sean maximizados. Por tanto, la cautela se impone, más aún en un momento en el que la economía está muy débil y la inflación se sitúa por encima del límite superior (IPC de 6,93\% en julio de 2020).
Finalmente, el 31 de agosto, el RBI ha anunciado un nuevo paquete de medidas de inyección de liquidez para calmar las presiones del mercado sobre los bonos y asegurar unas condiciones financieras ordenadas.

\subsection{Medidas comerciales}

Durante los meses de marzo y abril se prohibió la exportación de mascarillas y todo tipo de equipos de protección, incluido el material con el que se confeccionan. Además, el Gobierno prohibió la exportación de catorce principios activos y sus formulaciones, entre ellos el paracetamol y la hidroxicloroquina, ambos muy demandados para tratar la COVID-19. Posteriormente, a medida que se ha ido asegurando el suministro para satisfacer la demanda doméstica, las restricciones/prohibiciones se han ido levantando y creando cuotas de exportación en su lugar. Además, se han suprimido temporalmente, hasta el 30 de septiembre, los aranceles y tasas a la importación de aquellos productos sanitarios que sirven para combatir la COVID-19 y de los insumos necesarios para producirlos, como, por ejemplo, ventiladores, mascarillas, equipos de protección personal, kits de diagnóstico, etc.

Por último, en línea con la nueva política de «India autosuficiente», la ministra de Finanzas anunció, el 16 de mayo, que se haría una lista de armas y plataformas cuya importación quedaría prohibida y solo podrían ser adquiridas localmente. De esta manera, se quiere garantizar que los equipos de defensa sean hechos o comprados en India. El Ministerio de Defensa anunció, el 9 de agosto, la prohibición de la importación de 101 productos de defensa, como, por ejemplo, munición, armas, radares, simuladores y otras plataformas. La prohibición entrará en $\triangleright$ 
vigor en diciembre de 2020 para 69 productos y en fases, desde diciembre de 2021 hasta 2025, para los restantes 32 productos. Además, el 10 de agosto, un segundo anunció clarificó que para que un producto sea considerado indio tiene que tener un determinado porcentaje de contenido local, lo cual restringe aún más la fabricación de los 101 productos prohibidos.

\subsection{Reformas estructurales}

El sábado 16 de mayo del presente año, la ministra de Finanzas comunicó la cuarta parte del paquete económico anunciado por Modi, que consistirá en la reforma estructural de ocho sectores de la economía: carbón, minerales, defensa, aviación civil, compañías de distribución de energía, compañías MRO (maintenance, repair and operation), energía atómica y aeroespacio.

Se espera que estas reformas den un nuevo impulso a estos sectores, desencadenen nuevas oportunidades de inversión, lideren una mayor producción y generen más empleo.

La quinta y última parte del paquete de estímulo fue anunciada el domingo 17 de mayo. Como novedades cabe destacar que no se iniciarán nuevos procedimientos concursales durante un año y además la deuda contraída durante esta crisis no será tenida en cuenta en dichos procedimientos. Además, el Gobierno central prevé la privatización de sus empresas públicas no esenciales y la fusión de sus empresas públicas que operen en sectores esenciales. Por último, se aumentará el límite de endeudamiento de los estados del $3 \%$ al $5 \%$ del PIB.

La valoración de todas estas medidas es mixta. Por un lado, los estímulos fiscales y monetarios han sido bienvenidos. Además, se ha aprovechado esta crisis para seguir ahondando en las reformas estructurales que tanto necesita India. Sin embargo, el anuncio de la nueva campaña de Self-Reliant India, y las medidas que de ella se derivan (limitar competencia extranjera en licitaciones, prohibición de importaciones, mayor consumo local del Make in India...), suponen un paso más en la política proteccionista que India lleva aplicando varios años.

\section{Retos pendientes}

A nivel económico, el objetivo de la segunda legislatura de Modi era cerrar su mandato en el año fiscal 2024-2025 con un PIB indio de cinco billones de dólares. Alcanzar esta cifra, después de la desaceleración del año 2019, exigía crecimientos superiores al $8 \%$ en los años posteriores. Este objetivo, que ya se juzgaba excesivamente optimista y electoral, se ha evaporado con la crisis de la COVID-19.

En primer lugar, a corto plazo, es fundamental salir de la recesión actual lo más rápido posible y con el menor coste humano. A nivel económico, las medidas se han valorado positivamente. El consumo público, que se ha incrementado un $33,7 \%$ en el primer trimestre del año 2020, ha soportado por el momento la demanda, pero no tiene capacidad para seguir amortiguando la caída. Por tanto, tiene que ser el consumo privado, seguido de la inversión, el que tome el relevo en los próximos meses. El margen fiscal está ya muy ajustado y las cuentas públicas se han deteriorado, con una caída del $30 \%$ de la recaudación en el primer trimestre del año 2020. Así, la deuda y los pasivos contingentes contraídos durante la pandemia van a condicionar la política fiscal los próximos años. 
En segundo lugar, a medio plazo, India debe recuperar la senda de crecimiento sólido de los últimos años manteniendo la ortodoxia de las políticas económicas y el ímpetu reformista. Este reto podría ser más difícil de alcanzar en el actual contexto de incertidumbre causado por la COVID-19. Además, la nueva política de Self-Reliant India podría suponer un freno al crecimiento indio. En el marco de esta nueva política se han prohibido determinadas importaciones de material de defensa, se pretende pasar a un régimen de licencias en determinados sectores, se ha limitado la participación de empresas extranjeras en determinadas licitaciones globales e India parece alejarse del libre comercio. Así, se ha negado a formar parte del Regional Comprehensive Economic Partnership (RCEP), que supone la creación de una zona de libre comercio en la zona de Asia-Pacífico, y es reticente a avanzar en otros acuerdos. Por tanto, compaginar con inteligencia el Self-Reliant India con el Make in India sin quedar fuera del comercio internacional se antoja fundamental. Si India quiere ser un líder mundial a nivel económico, debe erigirse como un modelo a seguir en el ámbito multilateral, y esto es difícil con un proteccionismo rampante. El último informe del RBI hace hincapié en este aspecto y recomienda que la política comercial se centre en aumentar las exportaciones mediante la firma de acuerdos de libre comercio. En este contexto, considera que la finalización del acuerdo de libre comercio con la UE y un acuerdo pos-Brexit con Reino Unido podrían ser ventajosos.

En tercer lugar, si India quiere seguir atrayendo inversión extranjera y fomentando la inversión interna, es imprescindible mejorar en aquellos parámetros del Ease of Doing Business, donde el desempeño es más débil. En este sentido, la nueva plataforma para la presentación de impuestos inaugurada en agosto de 2020 va en la buena dirección. Aumentará la transparencia, eliminará los trámites presenciales de los contribuyentes y es previsible que India mejore su posición en el pago de impuestos en la clasificación del año que viene. No obstante, si India quiere convertirse en un hub manufacturero mundial, debe también continuar avanzando en todas aquellas reformas que faciliten el comercio transfronterizo, con especial énfasis en la logística y en las infraestructuras de transporte. India ostenta la posición 68. ${ }^{a}$ de 141 países en el Índice de Competitividad Global del World Economic Forum.

Por último, India tiene que acometer reformas pendientes en los mercados de productos y factores, así como en la ley de adquisición de tierra, para aumentar la competitividad del mercado. En este sentido, introducir flexibilidad en el mercado de trabajo se antoja fundamental. En primer lugar, si India quiere seguir siendo un líder mundial en industrias intensivas en trabajo (textil, farmacéutico, automoción) y además pretende aprovecharse de la eventual deslocalización de China, necesita dotar de flexibilidad a las empresas. En segundo lugar, esta reforma también debería reducir la dualidad entre el sector informal y el sector formal y fomentar la participación de la mujer en este último. Por otro lado, grandes proyectos se ven a menudo retrasados por problemas derivados de la adquisición de tierra. Así, es necesario redoblar los esfuerzos a nivel estatal para digitalizar los registros de tierra y simplificar todos los trámites y aprobaciones requeridos de manera que el proceso de adquisición de tierra se agilice. Ambas reformas tendrán un positivo impacto en el sector manufacturero, en la IED, en las exportaciones, y, en consecuencia, en un crecimiento más sólido con una balanza de pagos más equilibrada. 


\section{Bibliografía}

International Monetary Fund. Asia and Pacific Dept (2019). India 2019 Article IV Consultation. https:// www.imf.org/en/Publications/CR/Issues/2019/ 12/23/India-2019-Article-IV-Consultation-PressRelease-Staff-Report-Staff-Statement-andStatement-48909

Ministry of Finance, Government of India (2019). Economic Survey 2019-20. https://www.indiabudget. gov.in/economicsurvey/

Reserve Bank of India (2020). Annual Report 201920. https://www.rbi.org.in/Scripts/AnnualReportPublications.aspx?year=2020
UNCTAD (2020). World Investment Report 2020. https://unctad.org/en/pages/PublicationWebflyer. aspx?publicationid=2769

World Bank (2020). Doing Business 2020. https:// www.doingbusiness.org/en/reports/global-reports/doing-business-2020

\section{Páginas web consultadas}

Portal Invest India. https://www.investindia.gov.in

Portal Make in India. https://www.makeinindia.com/ home 